\title{
COMPARISON OF CRYSTALLOID PRELOADING AND CRYSTALLOID COLOADING IN EMERGENCY CAESAREAN SECTION FOR FETAL DISTRESS: A PROSPECTIVE STUDY
}

Malay Sarkar ${ }^{1}$, Ram Jiban Chanda², Debasish Bhar ${ }^{3}$, Dibyendu Roy ${ }^{4}$, Joydeb Mandal ${ }^{5}$, Prabir Biswas ${ }^{6}$

HOW TO CITE THIS ARTICLE:

Malay Sarkar, Ram Jiban Chanda, Debasish Bhar, Dibyendu Roy, Joydeb Mandal, Prabir Biswas. "Comparison of Crystalloid Preloading and Crystalloid Coloading in Emergency Caesarean Section for Fetal Distress: A Prospective Study". Journal of Evolution of Medical and Dental Sciences 2014; Vol. 3, Issue 07, February 17; Page: 1774-1781, DOI: $10.14260 /$ jemds/2014/2057

ABSTRACT: Spinal anesthesia is widely used for emergency and elective C/S delivery. However its main drawback is hypotension which may cause nausea, vomiting and cardiovascular collapse and loss of consciousness in mother as well as fetal hypoxia and acidosis due to placental hypo perfusion. AIMS AND OBJECTIVE: To compare the incidence of hypotension in intraoperative period and to compare the fetal outcome in two groups (Preloading and co loading group). STUDY DESIGN: Prospective randomized double blind study. MATERIALS AND METHOD: This study was conducted in the obstetric emergency OT of Malda Medical College. 100 primi gravid mothers aged between 1829 years with ASA-1 physical status posted for emergency C/S for fetal distress was randomly allocated for either preloading (Group P) or co loading (Group C). RESULT AND ANALYSIS: Fluid requirement is significantly less in group $\mathrm{C}$. There was no significant difference in the incidence of hypotension and ephedrine use. Fetal outcome in 1 min Apgar score in group C is significantly better as the baby could be delivered quickly in group C. CONCLUSION: Our study revealed that preloading can be safely avoided for spinal anesthesia in C/S for fetal distress. By using co loading method we can save valuable time required to deliver the baby and avoid circulatory overload without increasing the incidence of hypotension.

KEYWORDS: Caesarean section, co loading, fetal distress, hypotension, preloading, spinal anesthesia.

INTRODUCTION: Spinal anesthesia is widely used for emergency and elective C/S and has become the method of choice of anesthesia for C/S because of higher maternal morbidity and mortality associated with general anaesthesia. ${ }^{1}$ Beside being economical the advantages include rapid onset of action, better quality of sensory and motor block, ease of administration compared to epidural anesthesia and avoiding complications and risks associated with general anesthesia like failed intubation, risk of aspiration of gastric contents, depressant effects of general anesthesia on neonates.

It has been shown to block the stress response to surgery, decrease the intraoperative blood loss, decrease incidence of postoperative thromboembolism and reduce the risk of mortality and morbidity associated with high risk patients. ${ }^{2}$ However spinal anesthesia is not without disadvantages. It is associated with hypotension which is more common and profound in pregnant population. Preloading with crystalloids before spinal anesthesia has been widely practiced to prevent intraoperative hypotension by anaesthesiologist. ${ }^{3}$ This practice often hinders immediate administration of spinal anesthesia even in emergency $\mathrm{C} / \mathrm{S}$ posted for non-reassuring fetal status commonly known as fetal distress.

The wastage of time for preloading may further jeopardize the fetus or it may compel the anesthesiologist to go for general anesthesia which is known to have higher incidence of morbidity 
and mortality for mother and fetus.4-6 On the other hand hypotension associated with spinal anesthesia may impair the uteroplacental circulation which may also jeopardize fetal oxygenation. ${ }^{7}$ For the last two decades the concept of co loading (Infusion of fluid at the time of administering spinal anesthesia) has come to vogue and several studies both in pregnant and non-pregnant population were done.8,9 In our study we have compared crystalloid preloading and crystalloid co loading in emergency $\mathrm{C} / \mathrm{S}$ for fetal distress. The study was conducted to compare the incidence of hypotension intra operatively and fetal outcome in two groups.

MATERIALS AND METHODS: After taking ethical committee clearance and informed patient consent the study was conducted in the emergency obstetric OT of Malda medical college. 100 primi gravid patients of age group 18-29 belonging to ASA-1 physical status posted for emergency C/S for fetal distress were randomly allocated in two groups- Group P (Preloading group) and Group C (co loading group).

\section{Inclusion Criteria:}

1. Term pregnant patients (gestational age between 37 completed weeks to 42 weeks with cephalic presentation).

2. Clinical evidence of fetal distress ${ }^{10}$

a) $\mathrm{FHR}>160 / \mathrm{min}$ or $<110 / \mathrm{min}$.

b) FHR takes long time to come back to baseline after contraction phase passes off.

c) Irregular heartbeat.

d) Meconium stained liquor.

\section{Exclusion criteria:}

a) IUGR baby.

b) Medical or surgical complications of mother.

c) Absolute or relative contraindication of spinal anesthesia.

d) If the patient develops PPH.

Baseline heart rate, blood pressure (NIBP) and $\mathrm{SPo}_{2}$ were measured after transferring the patient to Operation Theater in a modified supine position with at least 15-left lateral tilt. One 18G cannula was inserted to all the patients and infusion of Ringers Lactate (RL) was started. Patients belonging to Group P received RL at a rate of $15 \mathrm{ml} / \mathrm{kg}$ over 20 minutes prior to administering spinal anesthesia (Preloading). Patients in Group C received same infusion at a rate of $20 \mathrm{drops} / \mathrm{min}$ prior to spinal anesthesia just to make the cannula patent. Group C patients received $15 \mathrm{ml} / \mathrm{kg}$ over 20 minutes after administering spinal anesthesia (co loading) and $20 \mathrm{ml} / \mathrm{min}$ after 20 minutes.

Group $\mathrm{P}$ patients received $\mathrm{RL}$ at the rate of $20 \mathrm{ml} / \mathrm{min}$ after spinal anesthesia was administered. Infusion RL was continued at the rate of $20 \mathrm{ml} / \mathrm{min}$ up to 1 hour after starting the operation in both the groups and then reduced to $10 \mathrm{ml} / \mathrm{min}$ if operation is continued beyond 1 hour. Administration of preoperative and intraoperative fluid was managed and monitored by a dedicated anesthesiologist. A second anesthetist who was unaware of patient preloading status administered spinal anesthesia and recorded the intraoperative vital status, the incidence of hypotension, bradycardia, hypoxia and fetal outcome etc. 
Hyperbaric 0.5\% Bupivacaine was injected intrathecally between $\mathrm{L}_{3-4}$ or $\mathrm{L}_{4-5}$ interspace with patient in sitting position at the dose of $0.25 \mathrm{mg} / \mathrm{kg}$ body weight up to maximum total dose of $15 \mathrm{mg}$ with 25G Quinke needle. The patient was then turned rapidly to modified supine position. The extension of spinal anesthesia was assessed by cold temperature discrimination using wet cotton balls ${ }^{11}$.Oxygen at the rate of $2 \mathrm{l} / \mathrm{min}$ was given to all patients via nasal prong till the delivery of the baby. Continuous monitoring of heart rate and $\mathrm{SPo}_{2}$ was done. SBP and DBP at 2min, $4 \mathrm{~min}, 6 \mathrm{~min}, 8$ min, $10 \mathrm{~min}, 15 \mathrm{~min}, 20 \mathrm{~min}, 25 \mathrm{~min}$ and 30 minutes were recorded and used for data analysis.

All blocks extended to above $\mathrm{T}_{6}$ level before surgery was allowed to start. Spinal induced hypotension (SIH), cardiovascular side effects (CVSE) and the condition of the baby were the main study outcome. SIH was defined as a decrease of $>30 \%$ in systolic blood pressure (SBP) or SBP $<90$ mm of Hg. ${ }^{9,11,12}$ CVSE were defined as SIH plus clinical symptoms of nausea, vomiting or faintness. ${ }^{13}$ At the beginning of the procedure patients were instructed to report any episode of nausea, vomiting or faintness occurring during the procedure. Patients were unaware of what treatment they had received.

All patients develop SIH and CVSE were treated with $200 \mathrm{ml}$ of bolus Ringer Lactate followed by $6 \mathrm{mg}$ of bolus Ephedrine. After 3 minutes if the SBP does not increase further dose of ephedrine (3 $\mathrm{mg}$ ) was repeated after 5 minutes if deemed necessary. ${ }^{14}$ Bradycardia was defined as heart rate < $60 / \mathrm{min}$ and treated with $0.6 \mathrm{mg}$ of atropine. Additional dose of $0.3 \mathrm{mg}$ was repeated after 2 minutes if necessary. Maximum height of block was identified during the procedure. Time of intrathecal injection and surgery, uterine incision and delivery, block and delivery, incidence of SIH and CVSE were noted. Total dose of vasopressor received and Apgar score of baby at 1 and 5 minutes were recorded. All patients received 10 units of injection oxytocin after delivery of the baby.

All values were expressed as mean \pm SD. Results were analyzed by unpaired $t$ test for parametric data and Mann Whitney U test were used for non-parametric data. Fisher's exact test and Chi square test were used for categorical data as appropriate. P value $<0.05$ was considered statistically significant. 15

\section{RESULT AND OBSERVATION:}

\begin{tabular}{|l|c|c|c|}
\hline & Group P (n=50) & Group C (n= 50) & P value \\
\hline Age in Years & $21.6 \pm 3.1$ & $21.1 \pm 3.2$ & $>0.05$ \\
\hline Weight in kgs & $53.7 \pm 5.3$ & $56.6 \pm 6.7$ & $>0.05$ \\
\hline Height in cms & $63.4 \pm 7.4$ & $65 \pm 8.4$ & $>0.05$ \\
\hline Block delivery interval (Minute) & $12.6 \pm 3.5$ & $13.1 \pm 4.2$ & $>0.05$ \\
\hline Uterine incision delivery interval (Minute) & $38.5 \pm 9.5$ & $36.8 \pm 8.9$ & $>0.05$ \\
\hline Duration of surgery (Minute) & $48.6 \pm 8.5$ & $46.9 \pm 7.9$ & $>0.05$ \\
\hline Level of block & $\mathrm{T}_{5}$ & $\mathrm{~T}_{5}$ & $>0.05$ \\
\hline
\end{tabular}

TABLE 1: Maternal characteristic and operative details

The two groups were compared in age, weight, height, duration of surgery and level of block. There is also no significant difference in uterine incision and delivery interval and block delivery interval among the groups. 


\section{ORIGINAL ARTICLE}

\begin{tabular}{|l|c|c|c|}
\hline & Group P(n=50) & Group C(n=50) & P value \\
\hline Preload volume(ml) & $805.45 \pm 79.7$ & $10.3 \pm 7.5$ & $<0.05$ \\
\hline Intraoperative fluid(ml) & $1053.56 \pm 57.80$ & $1456.39 \pm 78.90$ & $<0.05$ \\
\hline Dose of ephedrine(mg) & $7.6 \pm 2.5$ & $8.1 \pm 2.7$ & $>0.05$ \\
\hline Total fluid requirement till the end of surgery(ml) & $1859.01 \pm 60.67$ & $1466.89 \pm 68.71$ & $>0.05$ \\
\hline \multicolumn{2}{|c|}{ TABLE 2: Fluid and Ephedrine Administration } \\
\hline
\end{tabular}

This table shows that though intraoperative fluid requirement is more in Group $\mathrm{C}$, total amount of fluid received by Group C is significantly less compared to Group P. But there is no significant difference in the total dose of ephedrine administration in the two groups.

\begin{tabular}{|l|c|c|c|}
\hline & Group P(n=50) & Group C(n=50) & P value \\
\hline No. of patients became hypotensive & 17 & 16 & $>0.05$ \\
\hline Total episode of hypotension & 24 & 22 & $>0.05$ \\
\hline CVSE & 13 & 11 & $>0.05$ \\
\hline No of episode of hypotension requiring ephedrine bolus & 21 & 20 & $>0.05$ \\
\hline No of hypotension requiring second dose of ephedrine & 6 & 7 & $>0.05$ \\
\hline No of patients having bradycardia & 8 & 7 & $>0.05$ \\
\hline
\end{tabular}

TABLE 3: Intraoperative hypotension and bradycardia

Table 3 shows that there is no significant difference in the number of patients become hypotensive, episodes of hypotension, bradycardia and ephedrine requirement. 4 patient of Group $\mathrm{P}$ and 5 patients of Group $C$ received injection ondansetron $4 \mathrm{mg}$ i.v. for nausea and vomiting. Other patients developing CVSE responded well with correction of blood pressure.

\begin{tabular}{|l|c|c|c|}
\hline & Group P(n=50) & Group C(n=50) & P value \\
\hline Apgar score at 1 minutes & $7.6 \pm 0.76$ & $8.8 \pm 0.28$ & $<0.05$ \\
\hline Apgar score $<7$ at 1 minutes & 14 & 5 & $<0.05$ \\
\hline Apgar score at 5 minutes & $9.21 \pm 0.19$ & $9.32 \pm 0.18$ & $>0.05$ \\
\hline Apgar score $<7$ at 5 minutes & 3 & 2 & $>0.05$ \\
\hline
\end{tabular}

TABLE 4: Neonatal outcome

Fetal outcome in 1 minute Apgar is significantly better in group $C$ and significantly less no of babies of Group C had 1 min Apgar score less than 7 but no significant difference in both the groups at 5 minutes Apgar score.

\begin{tabular}{|c|c|c|c|c|c|c|c|c|c|c|c|}
\hline & $\begin{array}{c}\text { Pre } \\
\text { operative }\end{array}$ & $\begin{array}{c}0 \\
\text { min. }\end{array}$ & $\begin{array}{c}2 \\
\text { min. }\end{array}$ & $\begin{array}{c}4 \\
\text { min. }\end{array}$ & $\begin{array}{c}6 \\
\text { min. }\end{array}$ & $\begin{array}{c}8 \\
\text { min. }\end{array}$ & $\begin{array}{c}10 \\
\text { min. }\end{array}$ & $\begin{array}{c}15 \\
\text { min. }\end{array}$ & $\begin{array}{c}20 \\
\text { min. }\end{array}$ & $\begin{array}{c}25 \\
\text { min. }\end{array}$ & $\begin{array}{c}30 \\
\text { min. }\end{array}$ \\
\hline Group P & 131.43 & 134.67 & 130.46 & 126.70 & 120.56 & 116.45 & 114.12 & 107.48 & 108.65 & 109.76 & 113.68 \\
$(\mathrm{n}=50)$ & \pm 6.34 & \pm 5.69 & \pm 6.59 & \pm 7.44 & \pm 9.81 & \pm 10.37 & \pm 9.72 & \pm 8.95 & \pm 11.67 & \pm 9.45 & \pm 7.89 \\
\hline Group C & 130.47 & 130.56 & 126.78 & 122.78 & 118.67 & 115.67 & 112.76 & 116.65 & 116.65 & 118.75 & 117.65 \\
$(\mathrm{n}=50)$ & \pm 8.69 & \pm 8.97 & \pm 8.36 & \pm 9.45 & \pm 8.34 & \pm 11.45 & \pm 10.67 & \pm 8.78 & \pm 10.67 & \pm 8.67 & \pm 9.76 \\
\hline P value & $>0.05$ & $>0.05$ & $>0.05$ & $>0.05$ & $>0.05$ & $>0.05$ & $>0.05$ & $>0.05$ & $>0.05$ & $>0.05$ & $>0.05$ \\
\hline
\end{tabular}

TABLE 5: Intraoperative Systolic Blood Pressure (SBP) 
Intraoperative SBP change: There is no significant difference in SBP among the two groups except at 15 minutes, 20 minutes and 25 minutes when SBP in Group c is significantly higher than Group P.

\begin{tabular}{|c|c|c|c|c|c|c|c|c|c|c|c|}
\hline & $\begin{array}{c}\text { Pre- } \\
\text { operative }\end{array}$ & $\begin{array}{c}0 \\
\text { min. }\end{array}$ & $\begin{array}{c}2 \\
\text { min. }\end{array}$ & $\begin{array}{c}4 \\
\text { min. }\end{array}$ & $\begin{array}{c}6 \\
\text { min. }\end{array}$ & $\begin{array}{c}8 \\
\text { min. }\end{array}$ & $\begin{array}{c}10 \\
\text { min. }\end{array}$ & $\begin{array}{c}15 \\
\text { min. }\end{array}$ & $\begin{array}{c}20 \\
\text { min. }\end{array}$ & $\begin{array}{c}25 \\
\text { min. }\end{array}$ & $\begin{array}{c}30 \\
\text { min. }\end{array}$ \\
\hline Group P & 83.87 & 84.94 & 81.46 & 78.34 & 76.87 & 72.63 & 70.12 & 69.53 & 68.37 & 69.09 & 70.41 \\
(n=50) & \pm 5.78 & \pm 6.23 & \pm 6.79 & \pm 6.29 & \pm 6.21 & \pm 5.15 & \pm 7.34 & \pm 6.45 & \pm 6.78 & \pm 6.81 & \pm 6.59 \\
\hline Group C & 82.56 & 82.75 & 78.72 & 76.82 & 73.67 & 70.61 & 68.34 & 66.54 & 66.31 & 68.16 & 70.43 \\
(n=50) & \pm 6.73 & \pm 6.14 & \pm 5.06 & \pm 5.19 & \pm 5.97 & \pm 6.51 & \pm 6.59 & \pm 6.32 & \pm 7.34 & \pm 5.97 & \pm 6.10 \\
\hline P value & $>0.05$ & $>0.05$ & $>0.05$ & $>0.05$ & $>0.05$ & $>0.05$ & $>0.05$ & $>0.05$ & $>0.05$ & $>0.05$ & $>0.05$ \\
\hline
\end{tabular}

TABLE 6: Intraoperative diastolic blood pressure (DBP)

Intraoperative diastolic blood pressure change: There is no significant difference in two groups

\begin{tabular}{|c|c|c|c|c|c|c|c|c|c|c|c|}
\hline & Pre-operative & $\begin{array}{c}0 \\
\text { min. }\end{array}$ & $\begin{array}{c}2 \\
\text { min. }\end{array}$ & $\begin{array}{c}4 \\
\text { min. }\end{array}$ & $\begin{array}{c}6 \\
\text { min. }\end{array}$ & $\begin{array}{c}8 \\
\text { min. }\end{array}$ & $\begin{array}{c}10 \\
\text { min. }\end{array}$ & $\begin{array}{c}15 \\
\text { min. }\end{array}$ & $\begin{array}{c}20 \\
\text { min. }\end{array}$ & $\begin{array}{c}25 \\
\text { min. }\end{array}$ & $\begin{array}{c}30 \\
\text { min. }\end{array}$ \\
\hline Group P & 77.11 & 78.89 & 78.17 & 77.42 & 75.28 & 76.54 & 76.61 & 76.43 & 76.61 & 77.54 & 77.87 \\
(n=50) & \pm 5.67 & \pm 6.41 & \pm 7.29 & \pm 6.91 & \pm 7.35 & \pm 5.82 & \pm 6.78 & \pm 5.95 & \pm 7.06 & \pm 7.32 & \pm 6.34 \\
\hline Group C & 75.61 & 77.83 & 76.85 & 77.11 & 77.89 & 76.11 & 75.36 & 75.71 & 77.46 & 76.68 & 75.03 \\
(n=50) & \pm 6.43 & \pm 8.03 & \pm 7.98 & \pm 7.14 & \pm 7.82 & \pm 6.27 & \pm 6.21 & \pm 6.52 & \pm 8.38 & \pm 7.96 & \pm 5.97 \\
\hline P value & $>0.05$ & $>0.05$ & $>0.05$ & $>0.05$ & $>0.05$ & $>0.05$ & $>0.05$ & $>0.05$ & $>0.05$ & $>0.05$ & $>0.05$ \\
\hline \multicolumn{10}{|c|}{ TABLE 7: Intraoperative heart rate }
\end{tabular}

Intraoperative heart rate change: No significant difference was observed among two groups regarding heart rate.

DISCUSSION: More than 30\% of the patients receiving spinal anesthesia develop SIH according to Carpenter RL, Caplan RA, Brown DL et al ${ }^{16}$. There are several methods to reduce and prevent the incidence of hypotension i.e. left uterine displacement, use of vasopressor, leg elevation, massaging of calf muscle and preloading ${ }^{14}$. Preloading with crystalloid is one of the most common techniques among the anesthesiologist to reduce the incidence of hypotension. Previous studies have used 15$20 \mathrm{ml} / \mathrm{kg}$ RL for preloading in C/S.9, 17, 18 In our study we have preloaded our patient of Group P with $15 \mathrm{ml} / \mathrm{kg}$ of RL.

In CS of the patient with fetal distress where imminent delivery of the baby is warranted preloading may waste valuable time. As spinal anesthesia is not contraindicated and is less costly than GA, it is preferable to go for spinal anesthesia even in case of fetal distress. ${ }^{18}$ Most of the studies also have shown that Apgar score of these babies delivered under spinal anesthesia is better than those delivered under general anaesthesia.5, 18 In rural India where most of the patients coming to Govt. hospital are below poverty line, the cost of GA is an additional financial burden on the patients.

In addition to being time consuming preloading may cause circulatory overload in pregnant mother particularly after delivery which normally manifested by raised CVP. ${ }^{19}$ The extra load is not so harmful in patients with normal cardiovascular functions but may be potentially fatal in patients with myocardial insufficiency and pre eclampsia leading to pulmonary oedema. ${ }^{13}$ Pregnant patients are more susceptible to pulmonary edema due to increased pulmonary capillary permeability. ${ }^{20}$ 
In our study we have found no significant difference in the incidence of hypotension and CVSE among the two groups. Our observation is similar to previous studies.8,9,13,19 In our study though there is no statistically significant difference, the incidence of hypotension is slightly more in patients who were preloaded compared to those who were co loaded. The crystalloid fluid which was used for preloading 15-20 min before spinal anesthesia has relatively short intravascular life. Since 75\% of any crystalloid diffuses into interstitial space, its efficacy in expanding plasma volume is only transient ${ }^{21}$. On the other hand when fluid was administered along with administration of spinal anesthesia (Co loading), expanded intravascular compartment is filled up as there is sympathetic block induced vasodilatation and less chance of circulatory overload. In our study we have found that in the patients who received preloading has a slight higher initial SBP than those who did not. But fall of SBP is more in patients who were preloaded. The patients who received bolus fluid after spinal anesthesia (co loading) have significantly less fall in SBP than the other group (Table-5). Our observation is similar to the observations made by Jose L et al9.

Some of the studies have shown that preloading and co loading with colloid may be of more help to reduce the incidence of SIH and CVSE but the cost of colloid and risk of anaphylactic reaction with colloid do not make it a suitable and widely acceptable alternative of crystalloids ${ }^{22}$.

Regarding the neonatal outcome, we have not found any significant difference in Apgar score of neonates at 5 minutes but there is significant difference in neonatal outcome at 1 minute Apgar score between these two groups (Table -4). Significantly more no of the babies had 1 minute Apgar score less than 7 in preloaded groups compared to co loaded group. Previous studies ${ }^{13,19}$ have found no significant difference both in 1 minute and 5 minutes Apgar score but those studies were conducted in elective C/S without fetal distress where there was no urgency to deliver the baby. In our set up it was not possible to do umbilical blood PH and blood gas analysis so we relied totally on Apgar score.

CONCLUSION: From our study it can be concluded preloading can be safely avoided for spinal anesthesia in $\mathrm{C} / \mathrm{S}$ posted for fetal distress. By using co loading method we can save valuable time required to deliver the baby and avoid circulatory overload without increasing the incidence of hypotension. Regarding neonatal outcome 1 minute Apgar is better in co loading group.

\section{REFERENCES:}

1. Hawkins JL, Koonin L, Palmer SK, Gibbs CP. Anaesthsia related deaths during obstetric delivery in the United States, 1979-1990. Anaesthesiology 1997; 87: 1007.

2. Rodgers, Walker N, Schug S, Mckee Akelet H, Van Zundert A. Reduction of postoperative mortality and morbidity with epidural or spinal anaesthesia; result from overview of randomized trials. Br Med J 2000; 321: 1493.

3. Marx GF, Cosome EV, Wollman SB. Biochemical status and clinical condition of mother and foetus at caesarean section. Anaesth Analg1969; 48: 986-993.

4. Chestnut DH. Anaesthesia and maternal mortality. Anaesthsiology 1997; 86: 273-84.

5. Abbound TK, Nagappala S, Murukawa K et al. Comparison of the effects of general anaesthesia and regional anaesthesia for caesarean section as neonatal neurological and adaptive capacity score. Anaesth Analg 1985; 64; 996-1000. 
6. Downing JW, Howlton PC, Barclay A. Extradural analgesia for C/S: A comparison with general anaesthesia. Br J Anaesth 1979; 51: 367-73.

7. Corke BC, Dalta S, Ostheimer GW, Weiss JB, Alper MH. Spinal anaesthesia for caesarean section. The influence of hypotension on neonatal outcome. Anaesthesia 1982; 37: 658-662.

8. Banerjee A, Renato M Stocche, Angle Pamela, Stephen H. Halperr. Preload or coload for spinal anaesthesia for elective caesarean delivery: A meta-analysis, Can J Anaesth 2010; 57:24-31.

9. Jose L, Mojica, Hector J. Melendez, Leonelo E. Bautista. The timing of intravenous crystalloid administration and incidence of cardiovascular side effects during spinal anaesthesia: The result of a Randomised Controlled Trial. Anaesth Analg 2002; 94: 432-7.

10. Dutta DC. Text book of Obstetrics. $6^{\text {th }}$ Ed, 2004. 613-14.

11. Brail SJ, Greene N, M. Zones of differential sensory block during extradural anaesthesia. Br J Anaesth 1991; 66: 651-5.

12. Jackson R, Reid JA, Thorburn J. Volume reloading is not essential to prevent spinal induced hypotension at caesarean section. Br J Anaesth 1995; 75: 262-265.

13. Buggy D, Higgins P, Moran C. Prevention of spinal anaesthesia induced hypotension in the elderly; Comparison between preanaesthetic administration of crystalloids, colloids and no prehydration. Anaesth Analg 1997; 84: 106-10.

14. Samuel C. Hughes, Gershon Levinson, Mark A. Rosen. Shinder and Levinson's Anaesthesia for obstetrics. $4^{\text {th }}$ Ed. 206-207.

15. Paul S Miles, Tony Gin. Statistical methods for Anaesthesia and Intensive care. 1st Ed.51-71.

16. Carpenter RL, Caplan RA, Brown DC. Incidence and risk factors for side effects of spinal anaesthesia. Anaesthesiology 1992; 76: 906-16.

17. Sevgi Tercanli, Markus Schneider, Eva Visca, Irene Hosli. Influence of volume preloading on uteroplacental and foetal circulation during spinal anaesthesia for caesarean section in uncomplicated singleton pregnancies. Fetal diagnosis and Therapy 2002; 17: 142-146.

18. Ront CC, Akoojee SS, Rocke DA. Rapid administration of crystalloids preload does not decrease the incidence of hypotension after spinal anaesthesia for elective caesarean section. Br J Anaesth 1992; 68: 394-397.

19. Marx GF, Luykx WM, Cohen SE. Fetal neonatal status following caesarean section for foetal distress. Br J Anaesth 1984; 56:1009-1013.

20. MacLennan FM, MacDonald AF, Campbell DM. Lung water during puerperium. Anaesthesia 1987; 42: 141-147.

21. Carey JS, Scharschmidt BF, Culliford AT, Greenlee JE, Scott CR. Haemodynamic effectiveness of colloid and electrolyte solution for replacement of simulated operative blood loss. Surg Gynecol Obstet 1970; 131: 679-86.

22. Sharma Shiv. K, Gajraj Noor M, Elaine Sidawi J. Prevention of hypotension during spinal anaesthesia; a comparison of intravenous administration of Hetastarch versus Lactated Ringer's solution. Anaesth Analg 1997; 84: 1114. 


\section{ORIGINAL ARTICLE}

\section{AUTHORS:}

1. Malay Sarkar

2. Ram Jiban Chanda

3. Debasish Bhar

4. Dibyendu Roy

5. Joydeb Mandal

6. Prabir Biswas

\section{PARTICULARS OF CONTRIBUTORS:}

1. Associate Professor, Department of Gynaecology and Obstetrics, Malda Medical College and Hospital, Malda, West Bengal.

2. RMO Cum Clinical Tutor, Department of Anaesthesiology, Malda Medical College and Hospital, Malda, West Bengal.

3. Assistant Professor, Department of Anaesthesiology, Medinipur Medical College \& Hospital.

4. RMO Cum Clinical Tutor, Department of Gynaecology and Obstetrics, Malda Medical College and Hospital, Malda, West Bengal.
5. RMO Cum Clinical Tutor, Malda Medical College and Hospital, Malda, West Bengal.

6. Resident, Department of Physiology, RG Kar Medical College and Hospital.

\section{NAME ADDRESS EMAIL ID OF THE CORRESPONDING AUTHOR:}

Dr. Dibyendu Roy, Santi Niket Apartment, Flat - A/3, 14, Jagannath Dutta Lane, Kolkata - 700009.

E-mail: dibyendulive@gmail.com

Date of Submission: 22/01/2014.

Date of Peer Review: 23/01/2014.

Date of Acceptance: 31/01/2014.

Date of Publishing: 15/02/2014. 